\title{
If we build it, who will benefit? A multi-criteria approach for the prioritization of new bicycle lanes in Quebec City, Canada
}

\author{
Emily Grisé \\ McGill University \\ emily.grise@mail.mcgill.ca
}

\author{
Ahmed El-Geneidy \\ McGill University \\ ahmed.elgeneidy@mcgill.ca
}

\begin{abstract}
Many cities across the world are actively promoting cycling through investments in cycling infrastructure, yet ensuring that the benefits from these investments are distributed equally in a region and not benefiting only one group is an important social goal. The aim of this study is to develop a methodology that can help in identifying where new bicycle facilities can be built in a region while prioritizing investments for those who need them most. The study uses Quebec City, Canada, as an example since the city has recently made a strong commitment to provide safe and attractive bicycle infrastructure to its residents. It also uses a GIS-based grid cell model to identify priority areas for cycling investment in different parts of the city. This is followed by a proposal for a new set of facilities based on a multi-criteria approach. These proposed facilities are then evaluated through a level of usage analysis to determine which routes will provide the maximum benefit to existing and potential cyclists. Finally, an equity analysis is conducted to evaluate whether the new facilities will meet some of the travel needs of individuals residing in socially deprived neighborhoods. This step in the evaluation process proposes a new social equity component in bicycle planning processes. This research can be of value to planners, engineers and policymakers working toward investments in bicycle facilities because it shows the full process of planning and evaluating different cycling facilities while incorporating social equity principles.
\end{abstract}

\section{Article history:}

Received: November 13, 2016

Received in revised form:

September 25, 2017

Accepted: November 24, 2017

Available online: February 12,

2018

\section{$1 \quad$ Introduction}

The desirability of neighborhoods that facilitate the use of active modes of transportation is growing, however these neighborhoods may be out of reach for individuals who may highly benefit from the affordability, convenience and potential benefits to an individual's health offered by active travel. To reap the social, economic and environmental benefits associated with bicycle-friendly cities, many cities across North America are actively promoting investments in cycling infrastructure. However, recent evidence of an inequitable distribution of cycling infrastructure investment has been observed (Flana-

Copyright 2018 Emily Grisé \& Ahmed El-Geneidy

http://dx.doi.org/10.5198/jtlu.2018.1115

ISSN: 1938-7849 | Licensed under the Creative Commons Attribution - Noncommercial License 4.0

The Journal of Transport and Land Use is the official journal of the World Society for Transport and Land Use (WSTLUR) and is published and sponsored by the University of Minnesota Center for Transportation Studies. This paper is also published with additional sponsorship from WSTLUR. 
gan, Lachapelle, \& El-Geneidy, 2016), and concerns of infrastructure improvements as a reflection of gentrification efforts have been expressed (Lubitow \& Miller, 2013).

The objective of this paper is to present a practice-ready methodology to identify and prioritize locations for cycling infrastructure investments in the Quebec City, Canada. It is important to note that the methodology presented in this study was developed in collaboration with the local planning authority in Quebec City. Using a GIS-based model, we develop a prioritization index to identify high priority areas for the provision of new bicycle lanes, where we consider multiple criteria related to the safety and connectivity of the existing network, and where the demand for cycling trips exists. We then identify the optimal locations for new facilities based on the high-priority areas. To measure which proposed facilities would provide the maximum benefit to existing cyclists as well as individuals who may choose to convert from other transportation modes to cycling, we rank each proposed facility according to how many users can be expected to use each facility. In the last section of the study, we conduct an equity analysis of the proposed bicycle facilities to evaluate how these facilities will serve socially deprived neighborhoods and demonstrate how we can identify a list of facilities that will have the maximum benefit to a community.

In the following section of this paper we discuss the relevant literature on bicycle planning and the concept of equity in transportation planning. This is followed by an overview of the study area. We then proceed to the analysis section where the prioritization index is explained and presented, the proposed bicycle lanes are presented and evaluated, and the equity analysis is presented. In the final section, we discuss the findings and draw conclusions.

\section{$2 \quad$ Literature review}

\subsection{Bicycle infrastructure planning}

A growing body of literature suggests that in order to foster a bicycle culture and increase bicycling rates, appropriate infrastructure is essential (Pucher \& Buehler, 2016; Pucher, Dill, \& Handy, 2010). Pucher and Buehler (2008) conducted a thorough review of cycling infrastructure, cycling rates and policies in the Netherlands, Denmark and Germany, concluding that a comprehensive approach to bicycling, including the provision of safe and stress-free infrastructure, integration with other modes, and policies to restrict driving, is necessary to make cycling a safe and highly attractive mode of transportation. While cities in North America face resistance to policies that restrict driving or reduce parking, evidence indicates that expanding the bicycle network and increasing bicycle parking can have significant effects on cycling levels (Buehler \& Pucher, 2012). After studying 90 of America's largest cities, Buehler and Pucher (2012) concluded that there is a significant positive relationship between commuting rates and the availability of bike lanes and paths after controlling for land use, climate, socioeconomic factors, gasoline prices and public transit supply. A large body of research has pursued a greater understanding of how different facilities and environments affect cyclists' travel behavior. Findings on this topic appear to be dependent on a cyclists' trip purpose, characteristics among cyclists, as well as the type of bicycle facility (Aultman-Hall, Hall, \& Baetz, 1997; Broach, Gliebe, \& Dill, 2011; Howard \& Burns, 2001; Larsen \& El-Geneidy, 2011). Selecting what type of bicycle facility to build, should carefully consider the policy goal of a region (Larsen \& El-Geneidy, 2011). If the goal is to encourage new and novice cyclists, planners should prioritize new facilities with greater physical separation from automobile traffic. However, while this research is an integral part of the planning of new bicycle infrastructure, planners first need to determine the locations where bicycle infrastructure interventions are needed.

Literature that investigates how to locate and systematically prioritize where to build new cycling infrastructure has been limited to date. Rybarczyk and Wu (2010) posited that a comprehensive analysis of bicycle planning should consider both the supply, or the quality and safety of the network, as well 
as an understanding of the demand potential of a route. Accordingly, the authors integrated both these criteria in bicycle network planning in Wisconsin, USA. In a study of the cycle network in the Athens metropolitan region, Greece, Milakis and Athanasopoulos (2014) developed a methodology for cycle network planning using participative multi-criteria GIS analysis to incorporate the views of cyclists when choosing optimal network segments for new facilities. In a third study that presented a tool for bicycle facility planning, Larsen, Patterson, and El-Geneidy (2013) developed a GIS-based model that allows for flexibility to include data that is relevant to the study context and readily available, and that produces an easily interpretable grid-cell image of levels of priority across a region that is easily communicable to decision-makers and the general public. Using the Montreal, Canada, as a case study, the authors considered five indicators to prioritize cycling investment: observed and potential bicycle trips, stated preferences of cyclists regarding priority network improvements, bicycle-vehicle collision data and the network connectivity. The indicators were weighted equally and combined to create a prioritization index. However, none of the studies mentioned above looked at the equity impacts of these new facilities. In the present study, we develop a prioritization index similar to Larsen et al. (2013), using multiple criteria that are relevant to the Quebec case study. Building on this methodology, we present a method to rank proposed bicycle facilities according to their potential usage. We then evaluate the equity impacts of each proposed facility. However, first we will define the concept of equity in a transportation planning context.

\subsection{Equity and planning}

Equity can be broadly defined as the distribution of benefits and costs, and whether that distribution is considered fair. In 1996, Metzger defined equity planning as a responsibility that planners have to "influence opinion, mobilize underrepresented constituencies, and advance and perhaps implement policies and programs that redistribute public and private resources to the poor and working class in cities" (Metzger, 1996, p. 113). Failure to include social outcome goals in sustainability initiatives has been found to result in the inequitable distribution of the intended benefits (Flocks, Escobedo, Wade, Varela, \& Wald, 2011). A social outcome goal in the setting of bicycle planning, may refer to favoring new bicycle infrastructure projects in socially disadvantaged neighborhoods, which is considered a vertical equity approach. Vertical equity follows a progressive means of planning, where the division of benefits should be directed towards those with the greatest potential need.

Bicycles have great potential to provide an equitable, efficient and affordable means of transportation. However, with an inadequate supply of bicycle lanes and paths, users will likely experience a riskier network for bicycling. While perceptions of cycling as a fringe mode of transport or a last alternative to driving remain, cycling is being adopted for recreational purposes for the affluent, and for commuting purposes by millennials (Flanagan et al., 2016). Following an investigation of the distribution of cycling infrastructure investment in two American cities, Chicago and Portland, Flanagan et al. (2016) revealed disparities in cycling infrastructure investments in both cities. The authors observed that low income census tracts have been less likely to receive investment than more privileged areas. To mitigate these disparities greater consideration to how infrastructure is distributed is warranted.

To evaluate how well transportation plans will help to attain certain goals, various performance indicators such as accessibility measures have been considered (El-Geneidy, Cerdá, Fischler, \& Luka, 2011; Manaugh \& El-Geneidy, 2012). Manaugh and El-Geneidy (2012) evaluated how the 2007 Montreal transportation plan provides benefits for socially isolated and disadvantaged neighborhoods by evaluating accessibility and time-savings by public transit to job locations. To our knowledge no studies have incorporated equity principles throughout the bicycle planning process. For governments interested in providing public transit infrastructure in an equitable manner, Manaugh and El-Geneidy (2012) recom- 
mend asking three questions. First, where are the under-served populations located? Second, where are their places of employment? Third, how can they be better served? In this study, we consider these three questions, yet in a bicycle planning framework, to demonstrate how the inclusion of equity principles in the provision of new cycling facilities can be used when prioritizing among projects to ensure that transportation plans are equitable.

\section{Study area}

Quebec, Canada, is the second most populated city in the province of Quebec with a population of approximately 541,000 in 2015. In 2015 the City revealed its Vision Bicycle Travel (Ville De Quebec, 2016), where the City envisions a safe and connected bicycle network to attract and encourage cycling for everyday purposes, such as commuting. As a reflection of the densely-built city, $64 \%$ of trips made in Quebec are less than $5 \mathrm{~km}$, however around $65 \%$ of these trips are made by personal automobile (Ville De Quebec, 2016).

Prior to 2008, a majority of cycling paths in Quebec were intended for recreational purposes. However, in 2008 the City began to further develop the cycling network with the intention of promoting cycling for utilitarian trips. In 2016, the cycle network in Quebec consisted of over $424 \mathrm{~km}$ of network, and the location of the facilities is presented in Figure 1. A major challenge for the City is to design and build new cycling infrastructure in a densely-built and historic city. While the historic design is part of the charm of Quebec, there are many issues and challenges that the City must address to design new bicycle facilities and improve the current network. Quebec City is often referred to as lower and upper Quebec, where it is divided by an escarpment, and this change in elevation can be difficult for cyclists.

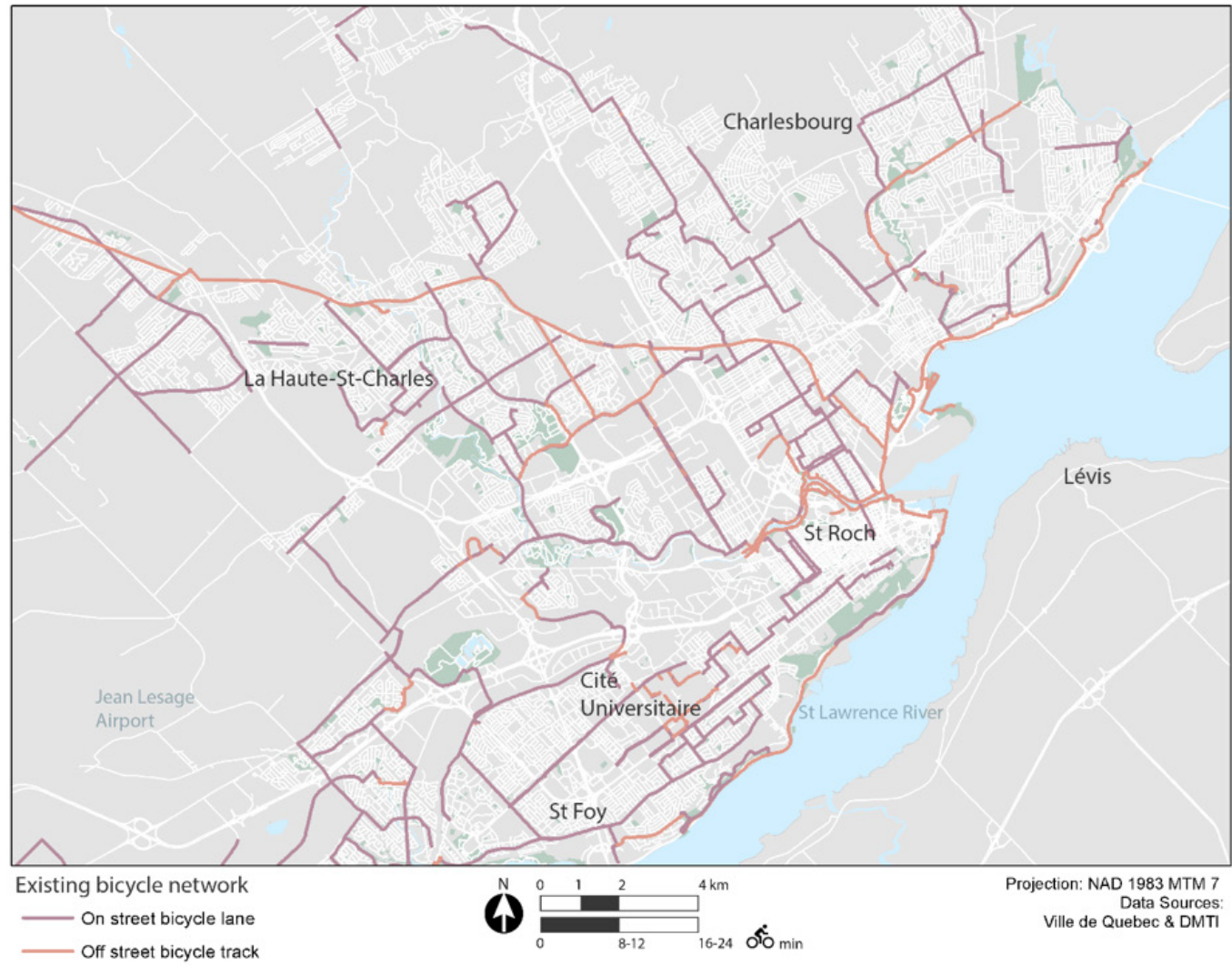

Figure 1: Context map of the existing bicycle network 
Despite these challenges, the City is currently looking to extend the bicycle network. To best address these challenges, a systematic method to locate new cycling facilities is necessary. In this study, we use a multi-criteria approach to prioritize the locations of new bicycle lanes. Note, in this study we do not consider facility type in the recommendation, rather we focus on where the city should build new infrastructure that will be most useful to current residents.

\section{$4 \quad$ Methodology, application, and results}

The objective of this study is to devise a methodology that is practice-ready, to guide the planning of new cycling facilities in an urban region. As there currently is $424 \mathrm{~km}$ of existing bicycling infrastructure in Quebec, we intend to provide recommendations of locations to expand the current cycling network in Quebec as well as identify areas that are currently underserved. The analysis is organized around four main steps, first we develop a prioritization index using a Geographic Information System, to identify regions for infrastructure investments. Second, we identify where to propose the new bicycle infrastructure based on the prioritization index results. Third, to prioritize among proposed projects, we evaluate the potential usage of each facility. Lastly, we consider the proposed routes from a vertical equity perspective to measure and prioritize the proposed facilities according to their potential impact on socially disadvantaged groups. To begin our analysis, we developed a multi-modal network, that merged the bicycle network with the street network, which also accounts for topography and preferences of cyclists.

\subsection{Development of bicycle network}

The network used in this study was created to include all links in the street network that are available for bicycle travel, as well as off-street bicycle and multiuse paths and private roads open to bicycles. Using the DMTI Spatial streets dataset elevation nodes we were able to determine elevation gains or losses for each street link. As previous research has found that cyclists have a strong sensitivity to slope (Broach et al., 2011), we modeled changes in elevation to our network, with the assumption that cyclists would alter their route, if possible, to avoid large gains in elevation. We applied the following formula to each street link:

Length $\left.+(1+(\text { ABS(Elevation change }) / \text { Length })^{*} 100\right)$

We also modified each road segment length to route a trip on a bicycle lane or cycle track, when possible. While there appears to be no consistent threshold in the literature regarding how far an individual is willing to diverge from their shortest path, Larsen and El-Geneidy (2011) found that respondents added on average $34 \%$ to their trip distance, however this varied based on facility type. Knowing that not all bicycle lanes and bicycle paths are perceived to be equal in quality and safety and that not all cyclists will choose to divert their route for bicycle infrastructure, we modeled routes so that an individual may travel an extra distance of $30 \%$ to have part or a majority of their trip on an off-street bicycle path, and allowed a route divergence of $20 \%$ from the shortest path for an on-street bicycle lane. Furthermore, when generating routes, one-way streets were open to bi-directional travel for cyclists, as select bicycle lanes in Quebec City are designed to allow for bi-directional travel. Following these adjustments to the street segment lengths, we applied this network in the Network Analyst tool in ArcGIS, using the shortest path algorithm, for determining all trips in the subsequent analyses. 


\subsection{Prioritization index for new bicycle infrastructure}

To identify high priority areas for the provision of new bicycle lanes, we consider a range of indicators related to where cycling trips are expected to take place in the city, the connectivity of the current network and stated opinions and safety concerns from existing cyclists in Quebec. In all, seven indicators are evaluated and are discussed below. This method was adapted from (Larsen et al., 2013) who presented a method for bicycle facility planning in Montreal, Canada. The selection of the indicators used in this study builds on the criteria used by the authors above, however later in the process the selection was slightly modified according to the Quebec City context and based on feedback from the local planning authority as this exercise was developed in collaboration with them.

\subsubsection{Existing and potential cycling trips}

The first series of indicators used in the analysis were from the routes of commuting trips by existing and potential cyclists. In this study, we focus on commuting trips, as this aligned with the goal of the region, being to increase the share of bicycle use for commuting trips. Furthermore, detailed data on commute trips is widely collected and readily-available. We observed existing cycling trips from two data sources. The first source of data was a survey conducted by the Transportation at McGill Research (TRAM) group in 2015 on bicycle transportation in Quebec City. From this survey we selected individuals who had made a cycling trip in the past month, and who provided the coordinates of their home and work or school location. We then used these coordinates to assign the approximate route that each individual had used to commute to work using network analyst in ArcGIS. The network described above was used to route the trips, and considered changes in elevation as well as the existing bicycle lanes and cycle tracks. We excluded any home or work/education locations that were outside of the study area, which was the Quebec Census Metropolitan Area (CMA). A total of 1071 trips were evaluated, with an average trip length of $6.9 \mathrm{~km}$. The second data source used to evaluate commuting trips made by bicycle in Quebec was from the 2011 Quebec Regional origin-destination (OD) survey provided by the Réseau de transport de la Capitale (Réseau de Transport de la Capitale, 2011), which is the public transit provider in the Quebec City area. This survey is conducted over the phone, and sampled $7 \%$ of the population. We observed the route of 379 trips with a mean trip length of $4.5 \mathrm{~km}$, after removing home or work locations outside of the CMA.

The second type of trips that we were interested in were short commute trips by travel modes other than bicycle. According to the 2011 OD survey, 71 percent of recorded trips were made by automobile, as either the driver or passenger, which demonstrates the auto-dominant travel behavior in Quebec City. We define potential cycling trips as non-bicycle trips that are a short distance and could be converted to bicycle. Specifically, these were trips under $5.8 \mathrm{~km}$ in length, which was the 75 th percentile distance of all commuting bicycle trips evaluated from the 2011 OD survey. A trip of 5.8 $\mathrm{km}$ would take on average 22 minutes by bicycle at an average pace of $16 \mathrm{~km} / \mathrm{h}$ (El-Geneidy, Krizek, $\&$ Iacono, 2007).

Two sources of trip data were used to evaluate potential cycling trips: the 2011 OD survey and the 2011 National Household Survey (NHS) Commuter Flows data (Statistics Canada, 2011). In total 19,511 home-work trips that were under $5.8 \mathrm{~km}$ from the 2011 OD survey were analyzed. The 2011 NHS Commuter Flows data records the census tract (CT) pair of an individual's home and work location, and indicates how many people have the same commute pattern. For this data, we used the centroid of each CT and determined the route between centroids. However, we do not know the travel mode used for these trips, therefore we can assume that some of these trips were made by bicycle, however the proportion of trips made by bicycle would be low given the low commuting mode share 
in Quebec City by bicycle (1.3\% in 2011 (Statistics Canada, 2015)). A total of 1140 trips were under $5.8 \mathrm{~km}$ and included in our analysis.

\subsubsection{Feedback of existing cyclists and network connectivity}

The next two indicators we incorporated were from feedback of existing cyclists about the current network. First, cyclists were asked to specify where they would like the city to install a new bicycle lane. Cyclists were asked "What street in Quebec City is in most need of a bicycle path or lane?" In subsequent questions the respondent was asked to specify the segment of that street they were referring to. Second, cyclists were asked to identify the most dangerous intersection in the city from their experience of cycling in Quebec. In the survey, participants were asked "What intersection in Quebec City is in most need of improvements for cyclists?" These survey questions provide invaluable feedback with regards to where to prioritize investments in bicycle infrastructure in Quebec City.

The final indicator used in the prioritization index was related to the connectivity of the existing bicycle network. A large portion of recent bicycle facilities in Quebec City were built in isolation, and built in succession with other road infrastructure projects and as a consequence the current bicycle network is very fragmented (as seen in Figure 1). Therefore, we identified locations in the bicycle network that are not connected to other facilities, which may be referred to as dangling nodes, and are priority locations to develop increased connectivity of the bicycle network.

\subsubsection{Combining, weighting and spatially aggregating indicators to a grid}

Once the data for the seven indicators was prepared, the next step was to spatially aggregate this information to a $300 \mathrm{~m}$ by $300 \mathrm{~m}$ grid cell which overlaid the study area. For example, we spatially joined the existing and potential cycling trips to the grid cells, to determine how many unique trips passed through each grid cell. A higher number of trips passing through a particular grid cell would suggest that this area is a suitable location for infrastructure investments. While in the case of the dangerous intersections indicator, we measured the number of individuals that identified an intersection located in that respective grid cell. Once all indicators were spatially aggregated to the grid cells, each indicator was standardized. The standardized score of each of the seven indicators is presented in Figure 2.

To combine all seven indicators into one priority index we used a weighting scheme, where we applied a higher weight to indicators related to where existing cyclists identified dangerous intersections and what streets are in greatest need of bicycle lanes, and to the connectivity of the street. These three indicators were given a weight of 2 . In regard to observed and potential cycling trips, we applied a weighting of 0.5 to potential cycling trips and a weighting of 1 to existing bicycle trips. Applying weights can vary based on the regions' priorities and can help in reducing some of the bias that might be present due to counting the potential cyclists from two data sources. While each of the indicators were deemed important for the use of developing the prioritization index, the weighting scheme applied here allowed for the stated preferences of cyclists' to be given a higher priority in the index given the utility of user feedback in understanding the optimal location for bicycle infrastructure investments (Milakis \& Athanasopoulos, 2014). The final result is presented in Figure 3. 


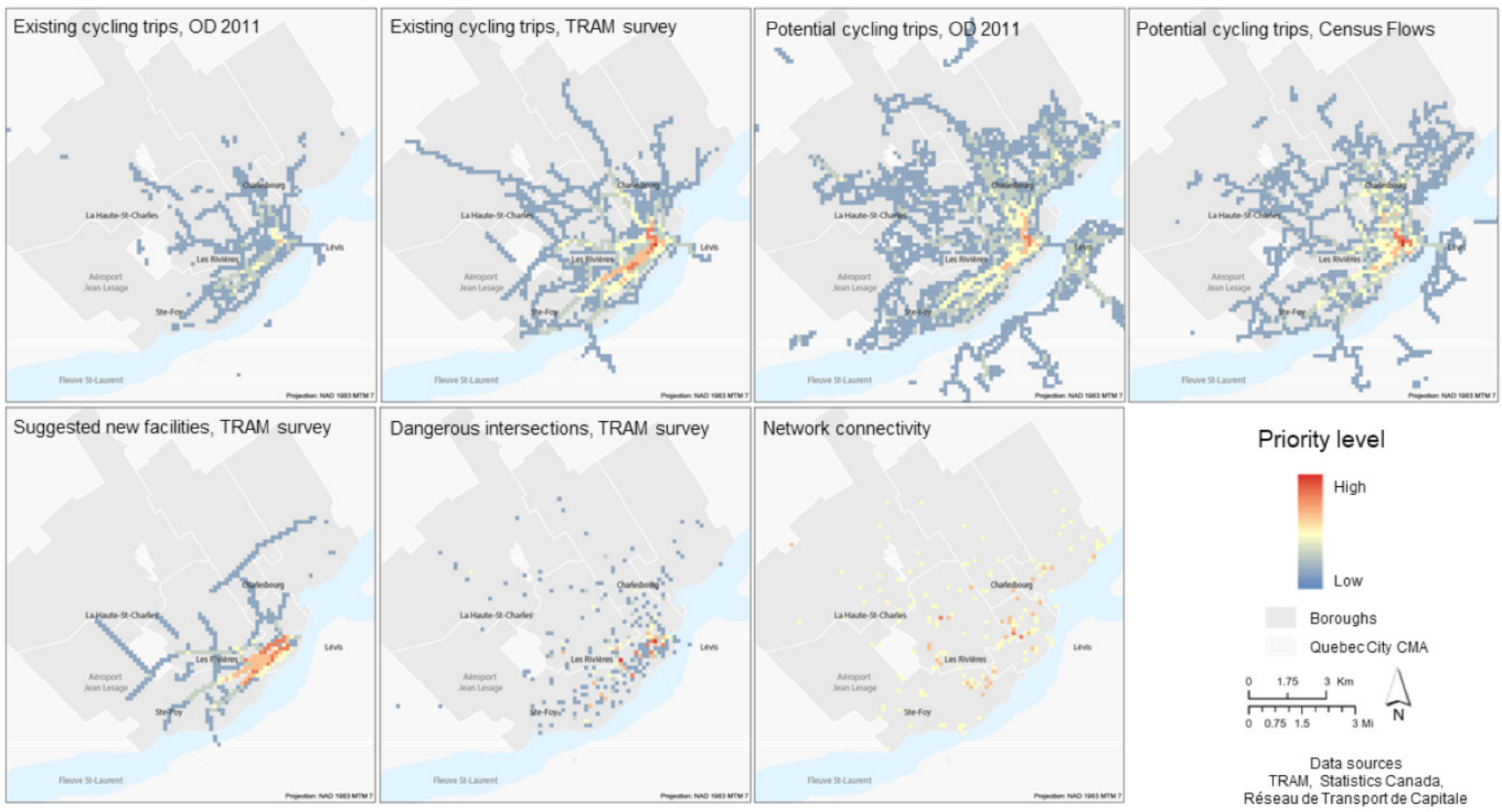

Figure 2: Standardized result of each indicator
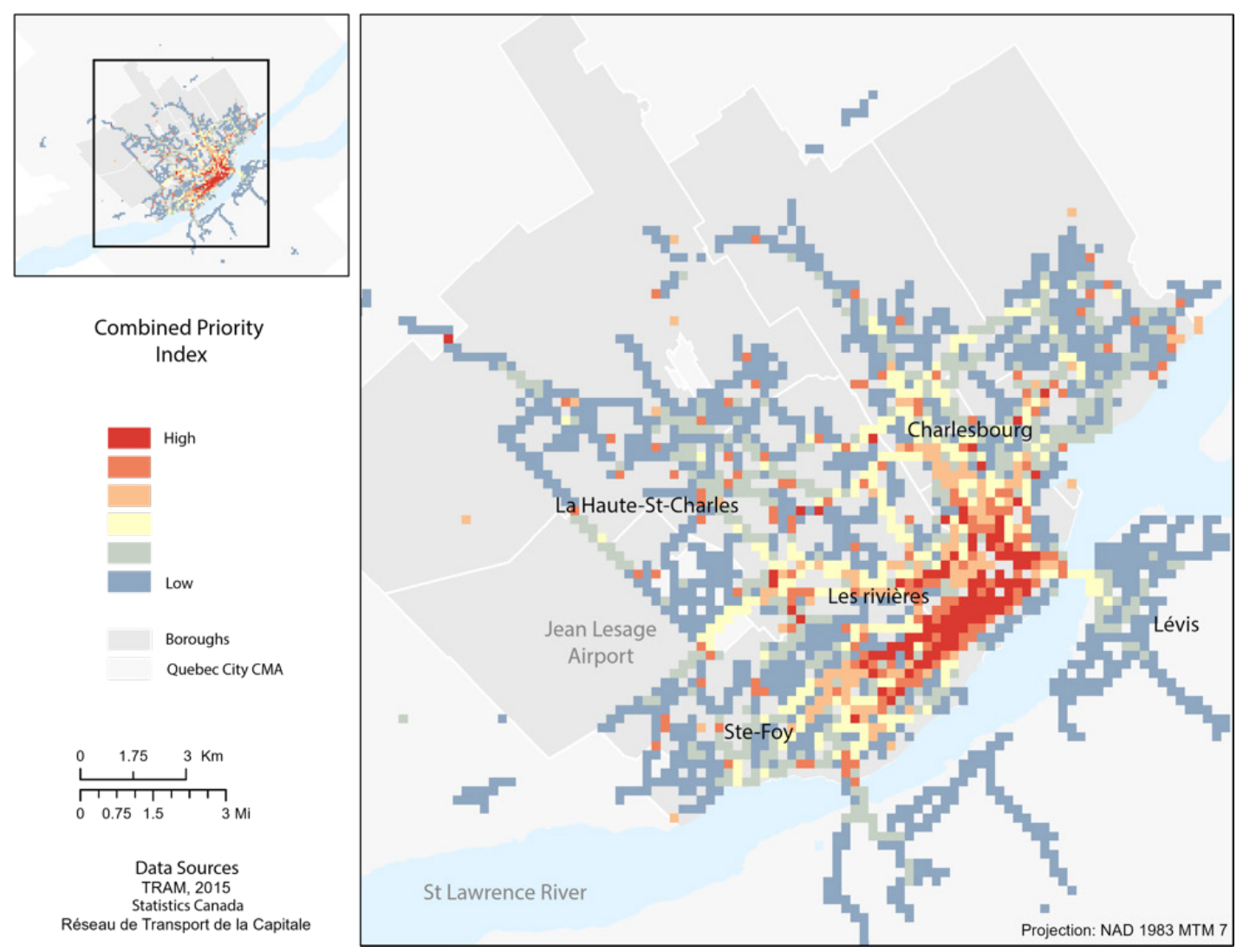

Figure 3: Final priority index 
Looking closely at the final priority index, there is a corridor located in downtown Quebec that could be considered as a priority zone, where future cycling investments would likely be beneficial to the greatest number of existing and potential cyclists. Additional high priority corridors include northsouth connections between downtown and residential neighborhoods located north of downtown, such as Charlesbourg and Les Rivieres. The high priority for infrastructure investment in the downtown part of Quebec is evident across all seven indicators. It is particularly evident that cyclists want additional bicycle facilities downtown, where the most frequently identified dangerous intersections are located. Furthermore, the high demand of both observed and potential cycling trips downtown is evident in Figure 2, where there is a strong concentration of employment and is where Quebec City's major university is located. The use of a 300-meter grid cell enables us to locate an approximate area where facilities are needed. The next step is to focus in on these high priority grid cells and recommend along which street passing through the grid cells will a bicycle facility be proposed. This section of the methodology is explained in the next section in detail.

\subsection{Proposed new bicycle lanes}

After closely examining the prioritization index, we recommended locations for new bicycle lanes. The proposal of new facilities was based on where grid cells with the highest priority index were located, and by determining where new bicycle lanes are needed within the cells. In the high priority downtown corridor, the current network is highly fragmented and in need of a more direct east-west route as well as better north-south connections. Therefore, the proposed bicycle lanes downtown were based on the high priority grid cells and by considering where new lanes would improve the connectivity of the current bicycle network. We then considered corridors in the upper city where the existing network is fragmented and there appears to be a strong need for new bicycle infrastructure. Finally, we carefully examined the network visually to identify where gaps in the network are and where connections to the existing network are needed in order to increase the safety of the network. Figure 4 presents the proposed bicycle lanes overlaid on the grid cell prioritization index. 


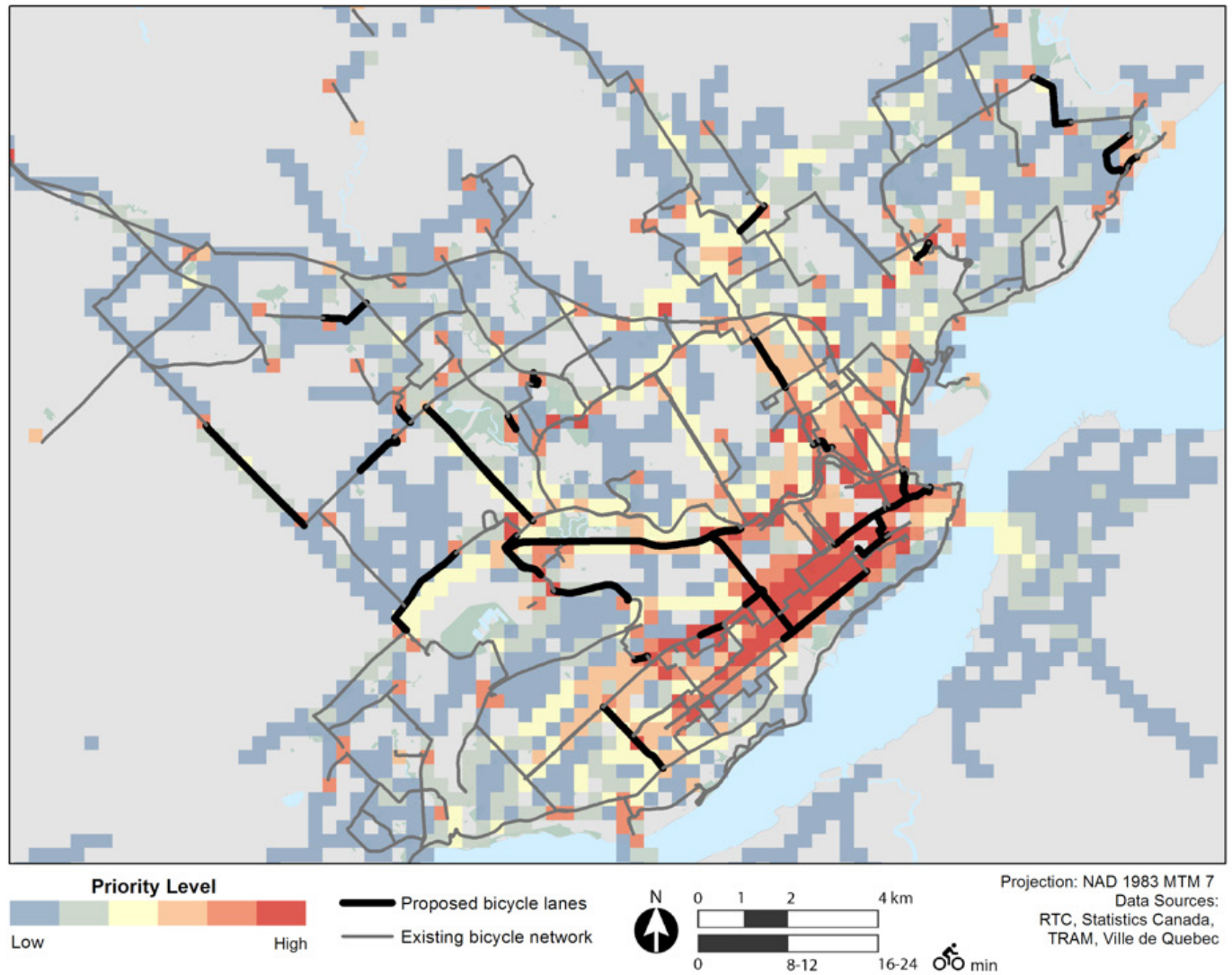

Figure 4: Display of proposed facilities over top the priority results

To verify the proposed bicycle lanes, we consulted individuals with local knowledge of the city and with cycling experience in Quebec, as well as with the local planning authority. Feedback for the proposed lanes was predominantly related to a lack of feasibility of proposed streets (i.e., streets that are too narrow or busy bus corridors). Furthermore, the feedback given indicated how to best utilize the current infrastructure, for example by connecting the existing elevator to a bike lane (as there is a very steep gradient between the lower and upper city). After revising our proposed bicycle lanes, a map of the proposed new network is displayed in Figure 5. 


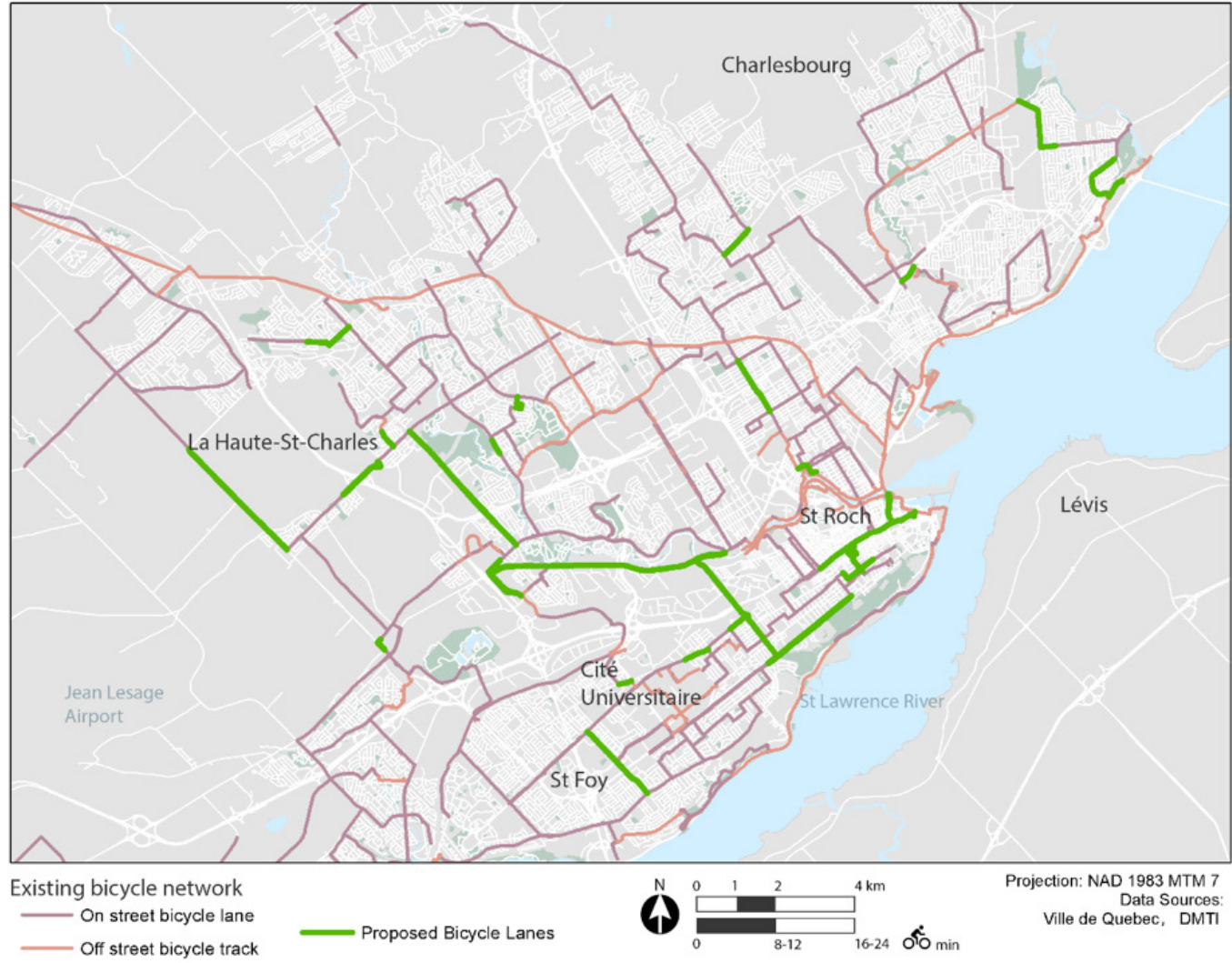

Figure 5: Proposed new bicycle network

While the proposed network is an ideal one, the Quebec City has a limited budget and can only accommodate a certain number of projects every year. Accordingly, setting a priority among the proposed links is an important step towards constructing these new facilities in phases.

\subsection{Measuring usage of proposed facilities}

Following the proposal of new bicycle lanes, we estimated the potential usage of each facility. In other words, we wanted to predict which new bicycle investment would serve and thus benefit the greatest number of people, which will allow us to prioritize among the proposed facilities. To estimate potential usage, we considered trips of existing cyclists who are either currently using these roads without bicycle lanes or who may alter their route to use these new facilities. Secondly, we considered the number of potential cyclists who may use these new bicycle lanes. The data for these trips was from the 2011 origindestination survey of home-work or educational trips. Here we used the expansion factor of each trip provided in the survey, which is derived from the number of occupied dwellings of the 2011 census by stratum and by household characteristics. Note, to evaluate each lane, we in some cases combined small street segments into one lane for analysis, or divided long streets into multiple segments to understand which street segments are most important.

To determine the route of these trips we accounted for elevation as well as on street bicycle lanes and off-street bicycle tracks, consistent with the previous analysis of routing existing and potential cycling trips used in the prioritization index. Note, we adjusted our network to include the proposed bicycle lanes and adjusted the length of these segments according to the 20 percent diversion rate, assuming 
these are on-street routes. Using the existing and potential cycling trips, we measured how many more trips would occur on these street segments if a bicycle lane was added (since the diversion rate would route cyclists on these lanes if the distance of the diversion allowed), and calculated the increase in trips on each segment. In Table 1 we present the estimated number of additional trips that are predicted to take place on each proposed bicycle lane. The proportion of additional trips made on each proposed lane by existing cyclists is displayed in the table, to contextualize the number of existing cyclists that are either currently using the street without a bicycle lane or who we predict would divert their path to use the new bicycle lane. We presented 10 of the proposed lanes with the highest expected increase in users in Table 1, although the estimated number of trips on all proposed lanes are displayed in Figure 6, where graduated symbols were used to represent the estimated usage of each proposed bicycle lane.

The results indicate that for example on Av Cartier, 378 cyclists are estimated to use this street segment (without a bicycle lane), however if a bike lane was built on this segment the usage is expected to be 2298 users, which is a six-fold increase in usage and should be considered a high priority bicycle lane. The expected usage increase on Rue St Vallier E is 1531 additional trips, which is more than double the existing usage. The 10 proposed bicycle lanes presented are all predicted to be highly used by cyclists. However, some of the proposed bicycle lanes had a very low estimated usage increase, all of which were located in suburban neighborhoods. This is potentially a result of larger trip distances for individuals traveling from suburban neighborhoods to downtown. Alternatively, low increased usage may be because these proposed lanes are located on small street segments that connect existing bicycle paths that cyclists are already using, or these proposed lanes are located along the most direct path and similarly, cyclists are already using these streets. Needless to say, these projects with low predicted increases in usage would improve the bicycle network and likely have positive impacts on cycling rates in Quebec City.

Please note that the predicted numbers are for one-way home to work/school trips, which mostly represent early morning usage. This methodology is only applied to these morning trips to demonstrate its potential as a tool for bicycle infrastructure planning. To derive a complete measure of all day usage, returning trips and trips for other purposes can be included in future studies. A limitation in the analysis described above is the lack of equity considerations which will be addressed in the next section.

Table 1: Estimated increase in trips using proposed bicycle lanes

\begin{tabular}{|c|c|c|c|c|l|}
\hline Rank & $\begin{array}{c}\text { Existing } \\
\text { usage }\end{array}$ & $\begin{array}{c}\text { Predicted } \\
\text { usage }\end{array}$ & $\begin{array}{c}\text { Estimated usage } \\
\text { increase }\end{array}$ & $\begin{array}{c}\text { Proportion of new usage } \\
\text { from existing cyclists }\end{array}$ & Street \\
\hline $\mathbf{1}$ & 378 & 2298 & 1919 & $5 \%$ & Av Cartier \\
\hline $\mathbf{2}$ & 911 & 2442 & 1531 & $8 \%$ & Rue St Vallier E \\
\hline $\mathbf{3}$ & 1303 & 2541 & 1238 & $8 \%$ & Rue Arago O \\
\hline $\mathbf{4}$ & 888 & 1887 & 998 & $3 \%$ & Rte De L'église \\
\hline $\mathbf{5}$ & 1121 & 2088 & 967 & $14 \%$ & 3 Av O \& Av Du Colisée \\
\hline $\mathbf{6}$ & 935 & 1843 & 908 & $10 \%$ & $\begin{array}{l}\text { Rue Cadillac, Rue De L'espinay \& } \\
\text { Rue Jacques Cartier }\end{array}$ \\
\hline $\mathbf{7}$ & 892 & 1668 & 775 & $6 \%$ & Boul René Lévesque E \\
\hline $\mathbf{8}$ & 457 & 1182 & 725 & $5 \%$ & $\begin{array}{l}\text { Côte Badelard, Rue Lavigueur, Rue } \\
\text { Philippe Dorval, Rue Richelieu, Rue } \\
\end{array}$ \\
& & & & & Sutherland \& Av Turnbull \\
\hline $\mathbf{9}$ & 256 & 711 & 455 & $13 \%$ & Boul Jean Lesage \& Rue Vallière \\
\hline $\mathbf{1 0}$ & 654 & 1094 & 440 & $7 \%$ & Grande Allée O \& Boul Laurier \\
\hline
\end{tabular}




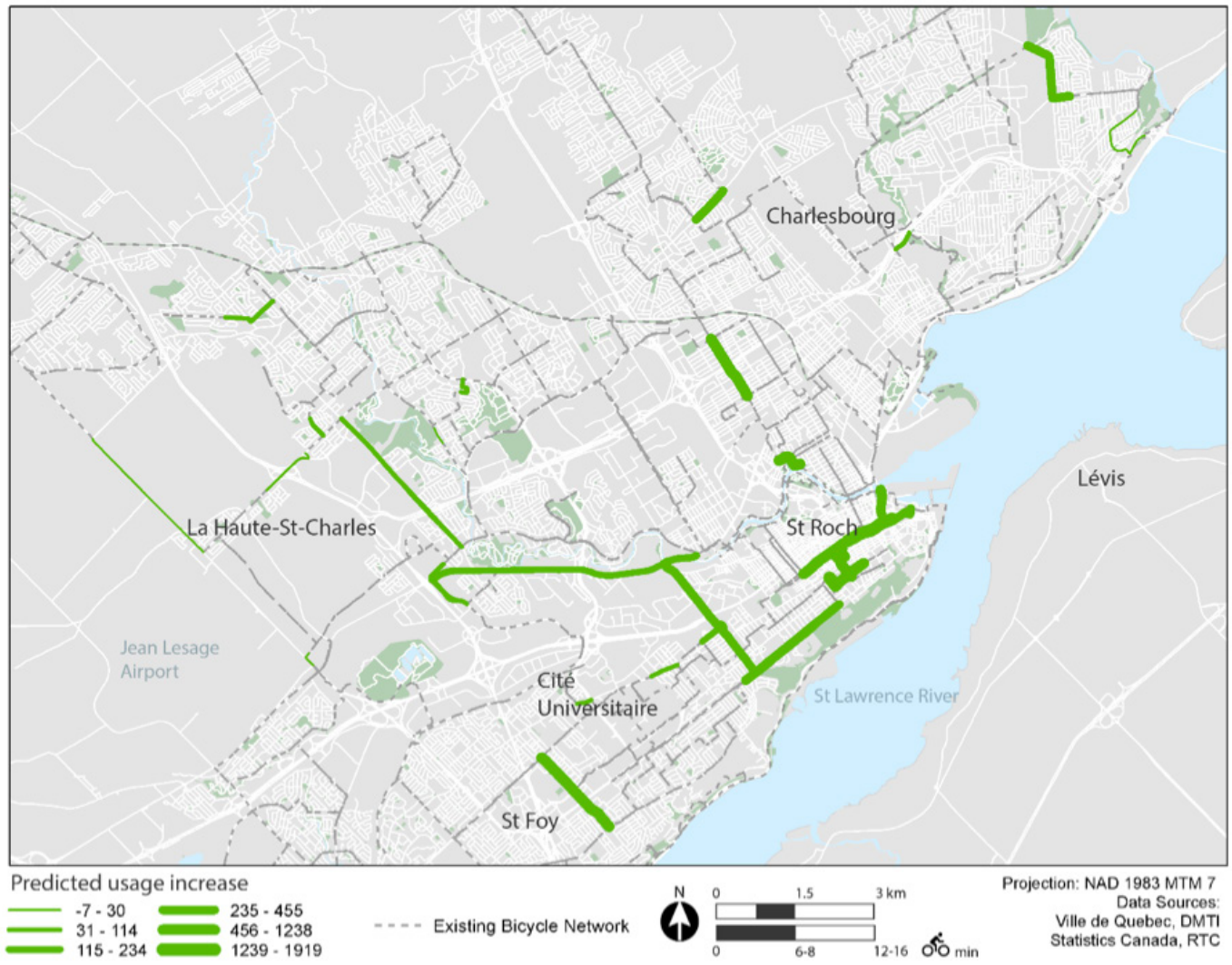

Figure 6: Map of predicted usage of new bicycle facilities

\subsection{Equity analysis}

To identify CTs with high proportions of socially deprived households, who we suggest are individuals who may particularly benefit from improved cycling facilities if they are useful for their daily commuting needs, we developed a social disadvantage index comprised of four indicators. Collected from 2011 Census data, the four variables include: median household income, unemployment rate, percentage of population that has recently immigrated (past five years), and percentage of households that spend 30 percent or more of their total household income on shelter costs. To ensure that these four variables correctly identify similar groups, a Pearson correlation matrix was used, and found high correlation estimates of over (0.42) among the selection variables. The selection of these four variables followed a method used by (El-Geneidy et al., 2016; Foth, Manaugh, \& El-Geneidy, 2013; Sánchez-Cantalejo, Ocana-Riola, \& Fernández-Ajuria, 2008).

The four variables were then standardized (Z-score) and combined with equal weight to derive an index of social disadvantage. This index of social disadvantage identifies CTs with high proportions of low income households, unemployed individuals, recent immigrants and households spending a high proportion of their income on rent. However, as we used aggregate census data, we must be cautious when interpreting these findings, as not all individuals residing in these socially deprived areas are in fact socially deprived, while also not all socially disadvantaged individuals live in an area classified as socially deprived (Townsend, Phillimore, \& Beattie, 1998). The index values were then grouped into deciles, where each decile contained $10 \%$ of the CTs. The decile containing the CTs with the highest level of social disadvantage was identified for further analysis. These CTs are displayed in Figure 7. 


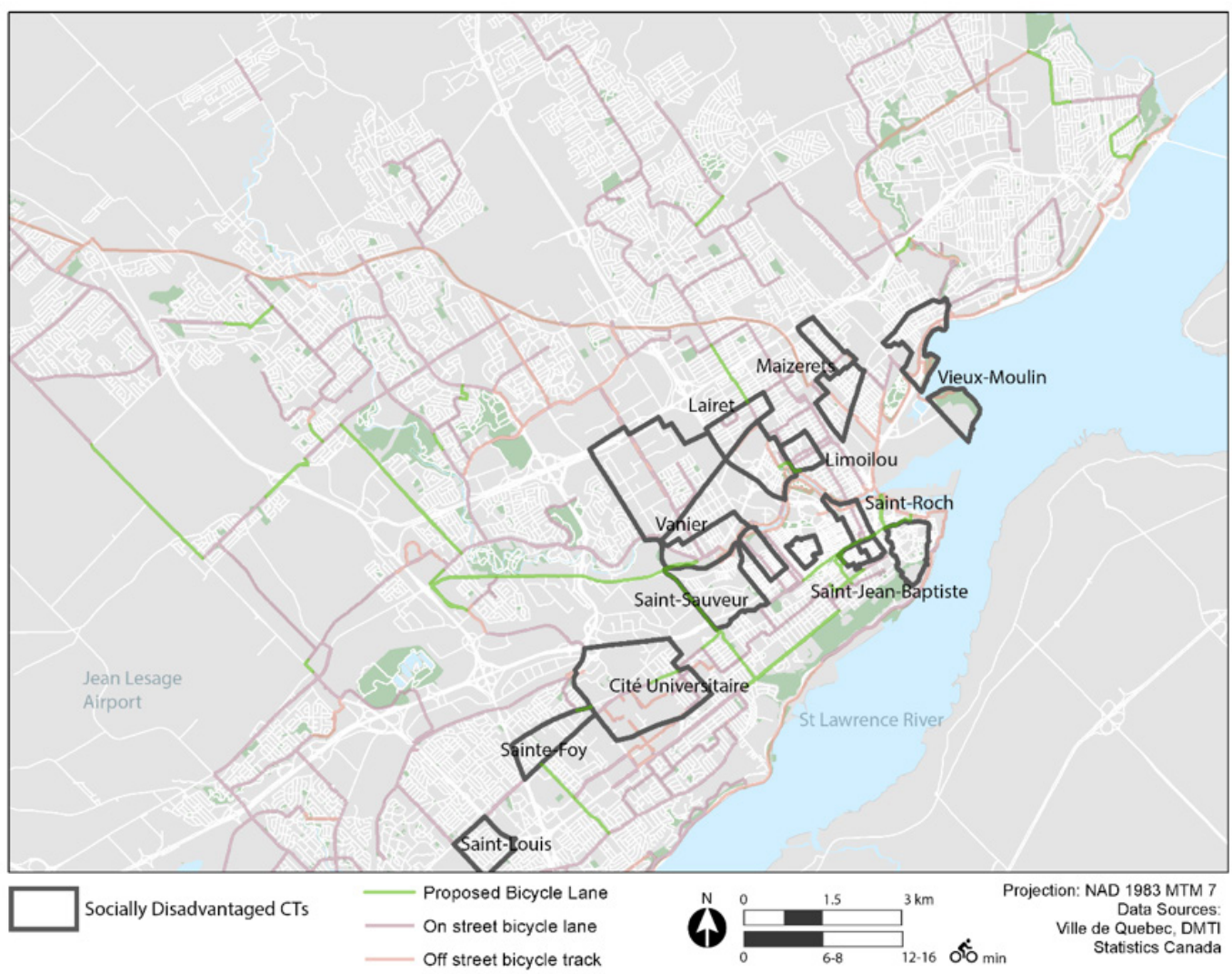

Figure 7: Identification of socially disadvantaged areas

What was of particular interest to us, was where individuals from these CTs travel to for their morning commute. Using 2011 origin-destination data, we considered all trips from home for the purpose of work or education that are currently made by bicycle (existing cyclists), as well as all home-work or education trips less than $5.8 \mathrm{~km}$ that are currently by other modes of travel (potential cyclists). To route these trips, the same network was used that was modified to include the proposed bicycle lanes, as well as the same penalties for elevation and incentives for use of bicycle facilities.

Similar to the above analysis, using all existing and potential cycling trips we estimated how many additional trips would be made on the proposed bicycle lanes. However, here we are interested specifically in home-work trips originating in a CT in the highest social indicator decile (10 percent most socially disadvantaged CTs). By using the home-work trip of these individuals, we are able to better understand their travel behavior and what bicycle facilities would best serve these individuals. Based on the potential number of additional cycling trips made by socially deprived individuals on each new bicycle facility, we then devised a new ranking of proposed facilities, and the 10 lanes with the highest estimated use is presented in Table 2. Figure 8 displays the predicted usage of each proposed bicycle lane, where the line thickness represents the estimated usage increase of trips originating in the most socially deprived decile. 
Table 2: Estimated increase in trips originating in socially deprived neighborhoods

\begin{tabular}{|c|c|c|c|c|l|l|}
\hline Rank & $\begin{array}{c}\text { All users } \\
\text { rank }\end{array}$ & $\begin{array}{c}\text { Existing } \\
\text { usage }\end{array}$ & $\begin{array}{c}\text { Predicted } \\
\text { usage }\end{array}$ & $\begin{array}{c}\text { Estimated usage } \\
\text { increase }\end{array}$ & $\begin{array}{l}\text { Proportion of new usage } \\
\text { from existing cyclists }\end{array}$ & Street \\
\hline $\mathbf{1}$ & 2 & 213 & 657 & 444 & $2 \%$ & Rue St Vallier E \\
\hline $\mathbf{2}$ & 1 & 29 & 390 & 362 & $1 \%$ & Av Cartier \\
\hline $\mathbf{3}$ & 3 & 238 & 586 & 348 & $1 \%$ & Rue Arago O \\
\hline $\mathbf{4}$ & 6 & 489 & 773 & 284 & $0 \%$ & $\begin{array}{l}\text { Rue Cadillac, Rue De L'espinay \& } \\
\text { Rue Jacques Cartier }\end{array}$ \\
\hline $\mathbf{5}$ & 8 & 121 & 313 & 193 & $2 \%$ & $\begin{array}{l}\text { Côte Badelard, Rue Lavigueur, Rue } \\
\text { Philippe Dorval, Rue Richelieu, } \\
\text { Rue Sutherland \& Av Turnbull }\end{array}$ \\
\hline $\mathbf{6}$ & 4 & 54 & 215 & 161 & $1 \%$ & Rte De L'église \\
\hline $\mathbf{7}$ & 9 & 58 & 204 & 146 & $3 \%$ & Boul Jean Lesage \& Rue Vallière \\
\hline $\mathbf{8}$ & 7 & 171 & 314 & 143 & $0 \%$ & Boul René Lévesque E \\
\hline $\mathbf{9}$ & 5 & 196 & 338 & 142 & $0 \%$ & 3 Av O \& Av Du Colisée \\
\hline $\mathbf{1 0}$ & 11 & 164 & 214 & 103 & $0 \%$ & Av St Sacrament \\
\hline
\end{tabular}

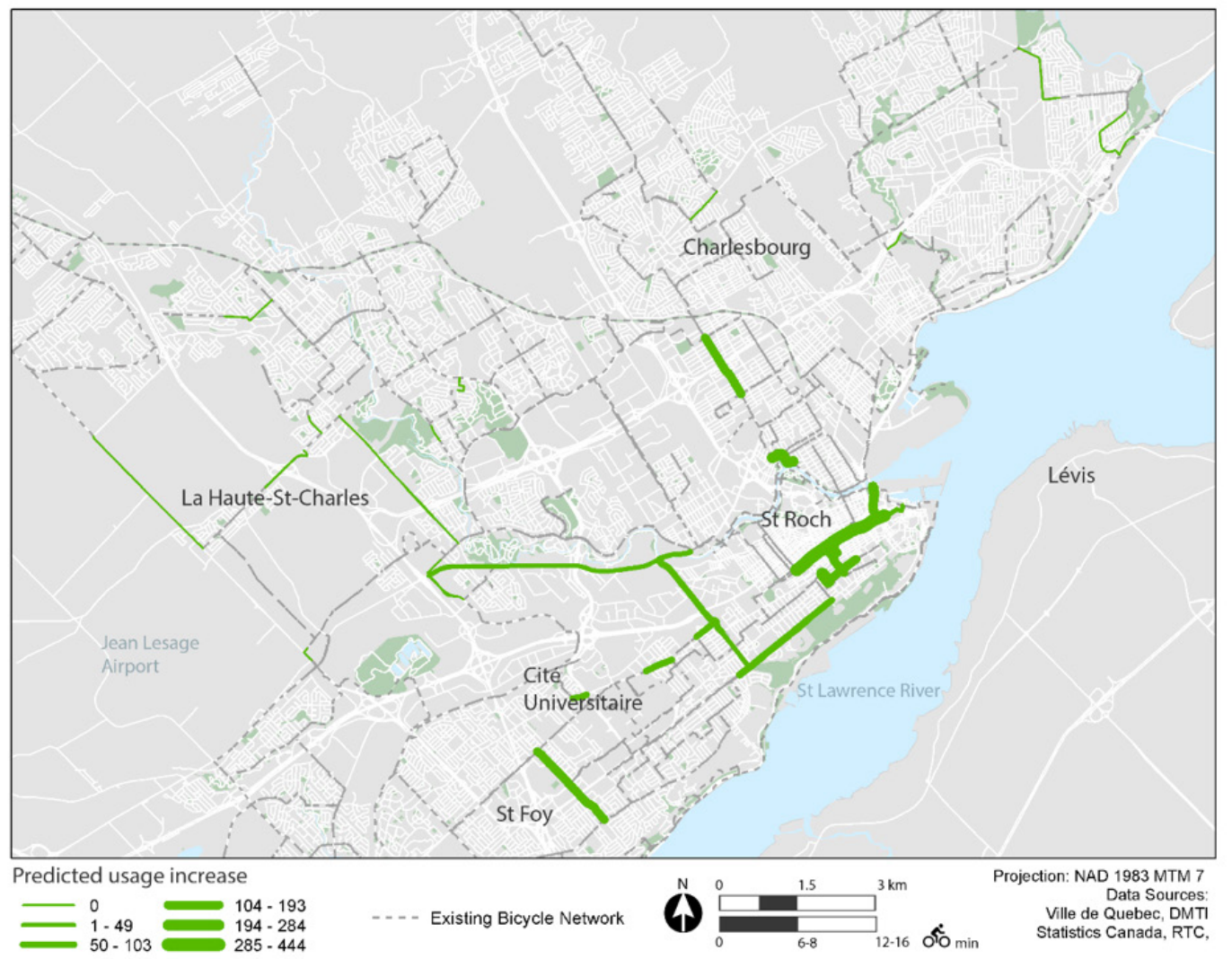

Figure 8: Map of predicted usage of new bicycle facilities of trips originating in the most socially deprived decile

Examining the proposed bicycle lanes according to which lanes would best serve socially deprived groups, we see modest changes in the ranking scheme when compared to the first ranking of the bicycle lanes according to all potential trips (both existing and potential cycling trips). For example, the pro- 
posed bicycle lane on Rue St Vallier E, is estimated to generate the highest number of trips originating in socially deprived CTs, however was ranked second based on total estimated usage (an additional 1531 trips). In other words, the proposed bicycle lane on Rue St Vallier E is estimated to be highly used by all existing and potential cyclists as well as to benefit socially disadvantaged individuals in their commute to work. In this study context, most of the proposed bicycle lanes that are estimated to be highly used by residents, will also serve CTs of high proportions of socially disadvantaged individuals. The proportion of the increased usage of each lane by existing cyclists relative to potential cyclists is very low compared to the estimated usage of all cycling trips. This suggests that a very limited number of commuting trips originating in socially deprived neighborhoods are currently being made by bicycle.

The above ranking can be easily applied by city officials to set priorities according to which bicycling facilities will be used the most by all existing and potential cyclists as well as to prioritize new infrastructure that will be used the most by socially disadvantaged groups to avoid previous issues that other regions faced by only advancing projects in socially advantaged neighborhoods.

\section{Discussion and conclusion}

For cities that are looking to foster a cycling culture through expanding their bicycle network, this study presents a methodology that can guide the planning and provision of new bicycle infrastructure. Using Quebec as case study for this paper, we used a multi-criteria approach to identify areas suitable for intervention. The data considered in this study included: observed and potential bicycle trips, the presence of dangling nodes or disconnected segments in the existing bicycle network, and suggested streets for new bicycle facilities as well as dangerous intersections identified through a cycling survey. The weighting scheme we applied assigned a higher weight to disconnected segments in the bicycle network and cyclists' feedback on where new facilities are needed and what intersections cyclists perceive as dangerous. No weight adjustment was applied to existing cycling trips, however to prioritize the importance of existing trips over potential cycling trips (as not all potential cyclists either will choose or are able to switch modes), a lower weighting was assigned to potential cycling trips. In future applications of this method, the weights applied to each indicator can be adjusted according to goals or priorities of the project or respective stakeholders, and a sensitivity analysis to measure the influence of different weighting schemes is recommended. Furthermore, while we recognized the importance of responses from cyclists in our study similar to previous work (Milakis \& Athanasopoulos, 2014), future studies of this sort should also actively involve infrequent or novice urban cyclists, because this group of cyclists is growing and failing to recognize the growth of this new cohort of cyclists may be detrimental for North American cities (Burke \& Scott, 2016). Furthermore, cyclists are heterogeneous (Damant-Sirois, Grimsrud, \& El-Geneidy, 2014), and cannot be expected to react similarly to efforts to increase cycling (Larsen \& El-Geneidy, 2011). Once the seven indicators were combined and the final prioritization index was prepared, we were able to identify areas in Quebec where facilities are needed. This method worked particularly well for identifying priority corridors, which was similarly observed by Larsen et al. (2013).

In the second phase of our analysis, we recommend where new bicycle lanes should be constructed according to the prioritization index. While suggesting what bicycle facility type to build was outside the scope of this study, the proposed bicycle lanes are intended to guide planners to where infrastructure investments are needed. However, in order to rank the proposed lanes according to estimated usage of existing and potential cyclists, we estimated how many more trips would occur on these street segments if a bicycle lane was added. Based on the change in trips on each segment, we ranked the proposed bicycle lanes accordingly. The ranking of proposed lanes can be very beneficial for prioritizing projects, especially when faced with budgetary constraints, coordination with other capital projects, and limited time during the year that is suitable for construction. The use of performance measures to evaluate trans- 
portation projects has been demonstrated in previous studies using accessibility indicators (El-Geneidy et al., 2011) and reductions in travel time (Manaugh \& El-Geneidy, 2012). However, the impact of bicycle lanes is a less tangible measure. While the number of users that will benefit from new bicycle lanes is a valuable measure for prioritizing projects, additional measures should be explored in the future.

After ranking projects according to potential usage by cyclists, we conducted an equity analysis to evaluate how the proposed bicycle facilities will benefit socially disadvantaged neighborhoods. We considered areas where high proportions of socially disadvantaged residents live, and where these individuals travel for work, and subsequently estimated how the proposed facilities will benefit socially deprived areas. According to the estimated increase in trips from socially deprived areas, we devised a new ranking of proposed facilities according to potential benefit to these users. In this study, we determined that most of the proposed bicycle lanes that were estimated to be highly utilized by potential and existing cyclists would also be highly beneficial to areas with high proportions of socially disadvantaged individuals. Considering disadvantaged areas early in the planning process will have considerable benefit to socially deprived groups to ensure that they are carefully considered in all stages of planning, rather than evaluating how well a transportation plan meets equity goals (Manaugh \& El-Geneidy, 2012).

Overall, this work is intended to provide planners and engineers with an empirical methodology to determine where new bicycle facilities are needed and how to measure their potential benefit to both existing cyclists and potential cyclists. The city of Quebec envisions cycling as an outlet to developing an attractive, dynamic, sustainable and efficient city. As exemplified in other North American cities, a greater supply of bicycle paths and lanes in cities is linked to higher rates of commuting by bicycle (Buehler \& Pucher, 2012). Consequently, the main contribution of this paper is to present a methodology for determining where bicycle lanes should be added and to provide a measure of the number of individuals who will benefit from the implementation of these new cycling projects. For the application of this approach in different contexts, we recognize that data availability can vary. While access to a rich source of data will enhance this approach to prioritizing bicycle infrastructure, in the absence of data such as user identified priority corridors, the methodology presented in this paper can still effectively guide planners or practitioners through the full process of planning and evaluating different cycling facilities while incorporating social equity principles.

As an important final step to the planning of new bicycle lanes, this work must be followed by a complete traffic analysis prior to moving forward with these proposed bicycle lanes. To ensure that the impact of new bicycle infrastructure on vehicle traffic is carefully understood prior to implementation, a study to evaluate the impacts of installing bicycle facilities on roads similar to Burke and Scott (2016) is required. The traffic study may alter the configuration of these bike lanes.

\section{Acknowledgements}

We would like to thank Jean-Francois Martel for providing us with data and his input throughout this project. We would also like to thank Marie-Pier Veillette for her input on the context of Quebec City as well as Nicole Ratti for her assistance with the maps. This work was supported by research grants from the Natural Sciences and Engineering Research Council of Canada as well as the Social Sciences and Humanities Research Council. 


\section{References}

Aultman-Hall, L., Hall, F., \& Baetz, B. (1997). Analysis of bicycle commuter routes using geographic information systems: Implications for bicycle planning. Transportation Research Record, 1578, 102 110.

Broach, J., Gliebe, J., \& Dill, J. (2011). Bicycle route choice model developed using revealed preference GPS data. Paper presented at the Transportation Research Board 90th Annual Meeting, January 23-27, 2011.

Buehler, R., \& Pucher, J. (2012). Cycling to work in 90 large American cities: New evidence on the role of bike paths and lanes. Transportation, 39(2), 409-432.

Burke, C., \& Scott, D. (2016). The space race: A framework to evaluate the potential travel-time impacts of reallocating road space to bicycle facilities. Journal of Transport Geography, 56, 110-119.

Damant-Sirois, G., Grimsrud, M., \& El-Geneidy, A. (2014). What's your type: A multidimensional cyclist typology. Transportation, 41(6), 1153-1169.

El-Geneidy, A., Buliung, R., Diab, E., van Lierop, D., Langlois, M., \& Legrain, A. (2016). Non-stop equity: Assessing daily intersections between transit accessibility and social disparity across the Greater Toronto and Hamilton Area (GTHA). Environment and Planning B: Planning and Design, 43(3), 540-560.

El-Geneidy, A., Cerdá, A., Fischler, R., \& Luka, N. (2011). Evaluating the impacts of transportation plans using accessibility measures. Canadian Journal of Urban Research, 20(1), 81.

El-Geneidy, A., Krizek, K., \& Iacono, M. (2007). Predicting bicycle travel speeds along different facilities using GPS data: A proof of concept model. Paper presented at the Proceedings of the 86th Annual Meeting of the Transportation Research Board, Compendium of Papers, January 21-25, Washington, DC.

Flanagan, E., Lachapelle, U., \& El-Geneidy, A. (2016). Riding tandem: Does cycling infrastructure investment mirror gentrification and privilege in Portland, OR, and Chicago, IL? Research in Transportation Economics, 60, 14-24.

Flocks, J., Escobedo, F., Wade, J., Varela, S., \& Wald, C. (2011). Environmental justice implications of urban tree cover in Miami-Dade County, Florida. Environmental Justice, 4(2), 125-134.

Foth, N., Manaugh, K., \& El-Geneidy, A. (2013). Towards equitable transit: Examining transit accessibility and social need in Toronto, Canada, 1996-2006. Journal of Transport Geography, 29, 1-10.

Howard, C., \& Burns, E. (2001). Cycling to work in Phoenix: Route choice, travel behavior, and commuter characteristics. Transportation Research Record, 1773, 39-46.

Larsen, J., \& El-Geneidy, A. (2011). A travel behavior analysis of urban cycling facilities in Montréal, Canada. Transportation research part D: Transport and Environment, 16(2), 172-177.

Larsen, J., Patterson, Z., \& El-Geneidy, A. (2013). Build it. But where? The use of geographic information systems in identifying locations for new cycling infrastructure. International Journal of Sustainable Transportation, 7(4), 299-317.

Lubitow, A., \& Miller, T. (2013). Contesting sustainability: Bikes, race, and politics in Portlandia. Environmental Justice, 6(4), 121-126.

Manaugh, K., \& El-Geneidy, A. (2012). Who benefits from new transportation infrastructure? Using accessibility measures to evaluate social equity in public transport provision. In K. Geurs, K. Krizek, \& A. Reggiani (Eds.), Accessibility and transport planning: Challenges for Europe and North America (pp. 211-227). London, UK: Edward Elgar.

Metzger, J. (1996). The theory and practice of equity planning: An annotated bibliography. Journal of Planning Literature, 11(1), 112-126. 
Milakis, D., \& Athanasopoulos, K. (2014). What about people in cycle network planning? Applying participative multicriteria GIS analysis in the case of the Athens metropolitan cycle network. Journal of Transport Geography, 35, 120-129.

Pucher, J., \& Buehler, R. (2008). Making cycling irresistible: Lessons from the Netherlands, Denmark and Germany. Transport Reviews, 28(4), 495-528.

Pucher, J., \& Buehler, R. (2016). Safer cycling through improved infrastructure. American Journal of Public Health, 106(12), 2089-2091.

Pucher, J., Dill, J., \& Handy, S. (2010). Infrastructure, programs, and policies to increase bicycling: An international review. Preventive Medicine, 50, S106-S125.

Réseau de Transport de la Capitale. (2011). Enquête Origine-Destination 2011 sur la mobilité des personnes dans la région de Québec.

Rybarczyk, G., \& Wu, C. (2010). Bicycle facility planning using GIS and multi-criteria decision analysis. Applied Geography, 30(2), 282-293.

Sánchez-Cantalejo, C., Ocana-Riola, R., \& Fernández-Ajuria, A. (2008). Deprivation index for small areas in Spain. Social Indicators Research, 89(2), 259-273.

Statistics Canada. (2011). 2011 National Household Survey Commuting Flow Data. Ottawa: Statistics Canada.

Statistics Canada. (2015). Commuting to work. Retrieved from http://www12.statcan.gc.ca/nhsenm/2011/as-sa/99-012-x/2011003/tbl/tbl1a-eng.cfm

Townsend, P., Phillimore, P., \& Beattie, A. (1998). Health and deprivation: Inequality and the north. Beckenham, UK: Croom Helm.

Ville De Quebec. (2016). Vision des déplacements à vélo. Retrieved from Quebec: https://www.ville.quebec.qc.ca/planification_orientations/transport/docs/vision_deplacements_velo.pdf 